\title{
ANALYSIS OF INITIAL FLOW DATA FROM MG-T/DOE AMOCO FEE NO. 1. WELL
}

TOPICAL REPORT

S. K. GARG

AUGUST 1981

WORK PERFORMED UNDER CONTRACT

DE-AC08-80-NV10150

SYSTEMS, SCIENCE AND SOFTWARE

P. O. BOX 1620

LA JOLLA, CA 92038

PREPARED FOR

DEPARTMENT OF ENERGY

NEVADA OPERATIONS OFFICE 


\section{DISCLAIMER}

This report was prepared as an account of work sponsored by an agency of the United States Government. Neither the United States Government nor any agency Thereof, nor any of their employees, makes any warranty, express or implied, or assumes any legal liability or responsibility for the accuracy, completeness, or usefulness of any information, apparatus, product, or process disclosed, or represents that its use would not infringe privately owned rights. Reference herein to any specific commercial product, process, or service by trade name, trademark, manufacturer, or otherwise does not necessarily constitute or imply its endorsement, recommendation, or favoring by the United States Government or any agency thereof. The views and opinions of authors expressed herein do not necessarily state or reflect those of the United States Government or any agency thereof. 


\section{DISCLAIMER}

Portions of this document may be illegible in electronic image products. Images are produced from the best available original document. 


\section{TABLE OF CONTENTS}

SECTION

PAGE

ABSTRACT ........................... i i

I. INTRODUCTION AND BACKGROUND ................. 1

II. ANALYSIS OF BUILDUP DATA .............. 4

III. HISTORY - MATCH CALCULATIONS ............... 11

IV. CONCLUDING REMARKS .................. 17

REFERENCES ....................... 18

APPENDIX - INITIAL FLOW TEST DATA NOTES . . . . . . . . 19 


\section{ABSTRACT}

Analysis of buildup data from the Initial Flow Test indicates that the MG-T/DOE Amoco Fee No. 1 Well penetrates a zone of relatively high permeability ( $150 \mathrm{md}$ ); this high permeability zone, however, extends to a radius of only about $200 \mathrm{ft}$ from the wellbore. The far field permeability (i.e., for $r>200 \mathrm{ft}$ ) appears to be rather low $(-11 \mathrm{md})$. No reservoir boundaries can be identified from the Initial flow test. The reservoir simulator MUSHRM together with the formation parameters inferred from the buildup data were employed to history match the observed drawdown/buildup pressures and flow data. The calculated buildup pressures closely agree with the measured values; the rather poor agreement between the measured and calculated drawdown pressures is ascribed to the uncertainties in the flow rate data. 


\section{INTRODUCTION AND BACKGROUND}

Since 1975, the U. S. Department of Energy (DOE) has undertaken an extensive deep drilling and well testing program to help evaluate the geopressured resources underlying the Gulf coast region of the United States. As part of this program, DOE executed a contract with Magma Gulf-Technadril (MG-T) of Houston, Texas to conduct the drilling, completion and testing of one geopressured geothermal well (i.e., MG-T/DOE AMOCO Fee No. 1 Well) in Cameron Parish, Louisiana. The subject well is located on a five acre test site approximately 15 miles south of Lake Charles, Louisiana. A description of the geology of the prospect area, well completion, test data on cores obtained from the well, and the test plan is given in a report by Durrett and Durham [1981].

In petroleum engineering and groundwater hydrology, flow testing is conducted routinely to diagnose the well's condition and to estimate formation properties. Flow testing of MG-T/DOE AMOCO Fee No. 1 Well is planned in three separate and distinct phases: (A) Phase I - Initial Flow Test - Reservoir Confirmation, (B) Phase II - Reservoir Limit Determination Test (2-3 weeks), and (C) Phase III - Long Term Demonstration Flow Testing at Commercial Design Rates ( 6 months). Initial flow testing of the MG-T/DOE AMOCO Fee No. 1 Well was conducted from June 19, 1981 to June 30, 1981 with flow rates upto $4200 \mathrm{Bbl} / \mathrm{D}$ in an effort to evaluate formation parameters for the geopressured sand perforated at $15,387 \mathrm{ft}$ to $15,414 \mathrm{ft}$ depth. The relevant data for the Initial Flow Test were supplied to Systems, Science and Software by Mr. Larry Durrett of Magma Gulf-Technadril. The present report is concerned with the analysis of the pressure/flow data obtained during the Initial flow Test. 
The MG-T/DOE AMOCO Fee No. 1 Well has 5-1/2 inch production 1 iner perforated over the interval $15,387 \mathrm{ft}-15,414 \mathrm{ft}$ (mean depth $=15,400.5 \mathrm{ft}$ ) in Miogyp sand. Bottom-hole pressure was measured using the Hewlett Packard quartz crystai gauge. Bottom-hole temperature $\left(-299^{\circ} \mathrm{F}\right)$ was recorded prior to the start of the flow test. Independent surface pressure recording capability was also available. A Halliburton turbine pulse meter was used to record brine flow rates; the turbine flow meter, however, was about $250 \mathrm{~B} / \mathrm{D}$ off zero, and could not be zeroed (see Appendix for details). The gas production rate was measured by flowing the gas through an orifice plate.

The pressure tool was set at a depth of $15,337 \mathrm{ft}$. The initial pressure at $15,337 \mathrm{ft}$ datum was measured at 12,053 psi. Assuming a static pressure gradient of $0.46 \mathrm{psi} / \mathrm{ft}$, the initial reservoir pressure (1.e., at 15,400.5 datum) becomes 12,082 psi. The brine produced from this well has a total dissolved solids content of $165,000 \mathrm{ppm}$ (i.e., 0.1487 by mass). With $p=12,082 \mathrm{psi}$, $T=299^{\circ} \mathrm{F}$, and $S=0.1487$, the $S^{3}$ methane/brine equation-of-state yields a methane content of 23.7 SCF/STB at saturation. The brine produced from the 15,387 - 15,414 ft Miogyp sand is, however, substantially less than saturated with respect to natural gas (i.e., 9-15 SCF/STB rather than 23.7 SCF/STB). In the following, it will be assumed that the methane content of the reservoir fluids is 14.7 SCF/STB.

The main purpose of this report is to analyze pressure drawdown and buildup data to evaluate formation parameters. For purposes of analysis, it is convenient to reduce the brine flow data to standard conditions; the procedures utilized to convert the flow data are discussed in the Appendix. We note here that the indicated changes in flow rate do not correspond to any noticeable changes in the pressure drawdown data. For this reason, we believe that the pressure drawdown data are of limited utility; we will accordingly 
concentrate on the analysis of the buildup data. It is appropriate to briefly discuss here the contents of the rest of this report. In Section II, we utilize conventional petroleum engineering/hydrology techniques to analyse buildup data to estimate permeability, skin factor and any indications of faults/mobility changes in the perforated zone. Analysis of buildup data indicates that the MG-T/DOE AMOCO Fee NO. 1 Well penetrates a zone of relatively high pemeability ( $150 \mathrm{md}$ ); this high permeability zone, however, extends to a radius of only about $200 \mathrm{ft}$ from the well. The far field permeability (i.e., for $r>200 \mathrm{ft}$ ) appears to be rather low ( - $11 \mathrm{md}$ ). No other reservoir boundaries/mobility changes can be identified from the initial test data. The estimated parameters from the buildup analysis are employed in the $s^{3}$ geopressured geothermal reservoir simulator (MUSHR) to perform calculations to history match the observed drawdown/buildup pressures and flow rates (Section III). Although the computed final flowing pressure displays excellent agreement with the observed final flowing pressure, the computed drawdown pressures show a generally poor agreement with the observations. This discrepancy between the computed and the observed drawdown pressures can be ascribed to uncertainties in the flow data. The calculated bulldup pressures, on the other hand, are in excellent agreement with the observations. 


\section{ANALYSIS OF BUILDUP DATA}

The MG-T/DOE AMOCO Fee No. 1 Well was flowed at varying rates from 18:18 hours on June 19, 1981 to 20:03 hours on June 22, 1981 for a total of 73.75 hours. For purposes of analysis, it is conventent to average the flow rate data over the following two periods (see Appendix):
A. 0 min $\leq t \leq 3942 \min$
$q_{c}=3420 \mathrm{STB} / \mathrm{D}$
B. $3942 \min \leq t \leq 4425 \mathrm{~min}$
$q_{c}-2610$ STB/D

Bottom-hole pressures were monitored continuously during the entire flow period. Subsequent to well shutin, pressure buildup was recorded for approximately 184 hours (i.e., from 20:03 hours on June 22. 1981 to $12: 13$ hours on June 30,1981$)$. Since the reservoir fluid is undersaturated with respect to natural gas, it is unlikely that the flow stream, at bottom hole conditions, would contain any free gas. Consequently, it is felt that classical single-phase analysis methods should be sufficient for analyzing the pressure buildup data.

Analysis methods for bulldup tests with widely varying flow rates before shutin are described by Earlougher [1977]. For infinite - acting systems, a plot of shutin pressure $P_{w s}$ versus a reduced time

$$
\sum_{j=1}^{N}\left(q_{j} / q_{N}\right) \log \frac{t_{N}-t_{j-1}+\Delta t}{t_{N}-t_{j}+\Delta t}
$$

should yield a straight line with slope $m$. Here $q_{j}$ is the flow rate during the time interval $t_{j-1}<t<t_{j}, t_{0}$ is $0, q_{N}$ is the final flow rate prior to shutin at $t=t_{N}$, and $\Delta t$ is the 
buildup time. Permeability $k$ and skin factor $s$ are given by:

$$
\begin{aligned}
\frac{k h}{\mu} & =\frac{162.6 \mathrm{q}_{N} B}{m} \\
s & =1.151\left[\frac{p_{1 h r}-p_{w f}}{m}-\log \frac{k}{\sigma C_{T} r_{W}^{2}}+3.23\right]
\end{aligned}
$$

where

$$
\begin{aligned}
B & =\text { formation volume factor } \\
h & =\text { formation thickness, ft } \\
\mu & =\text { fluid viscosity, } c p \\
& =\text { final pressure before shutin, psi } \\
P_{w f} & =\text { shutin pressure at } \Delta t-1 \text { hour extrapolated from the } \\
P_{1} h r= & \text { straight line, psi } \\
\phi= & \text { formation porosity } \\
r_{W}= & \text { well radius, ft } \\
C_{T}= & \text { total formation compressibility }\left(=((1-\phi) / \phi) C_{m}+\right. \\
& \left.C_{f}\right), \text { psi } \\
C_{m} & =\text { uniaxial formation compressibility, psi }{ }^{-1} \\
C_{f}= & \text { fluid compressibility, psi-1. }
\end{aligned}
$$

In the absence of measurements, we will assume that the uniaxial formation compressibility is of the order of $1 \times 10^{-6}$ $\mathrm{psi}^{-1}$. With $\mathrm{c}_{\mathrm{f}}-3 \times 10^{-6} \mathrm{psi}^{-1}$ and $\phi=0.22$, we obtain for $C_{T}$ :

$$
C_{T}=\frac{1-0.22}{0.22} 10^{-6}+3 \times 10^{-6}-6.5 \times 10^{-6} \mathrm{psi} .
$$

The buildup pressure data versus reduced time are plotted in Figures 1 and 2. It can be seen from figures 1 and 2 that two straight lines can be drawn through the buildup data; these straight lines have slopes of $32.1 \mathrm{psi} / \mathrm{cycle}$ and $430.5 \mathrm{psi} / \mathrm{cycle}$ respectively. The first straight line segment (slope $=32.1$ psi/cycle) yields for near wellbore permeability: 
a

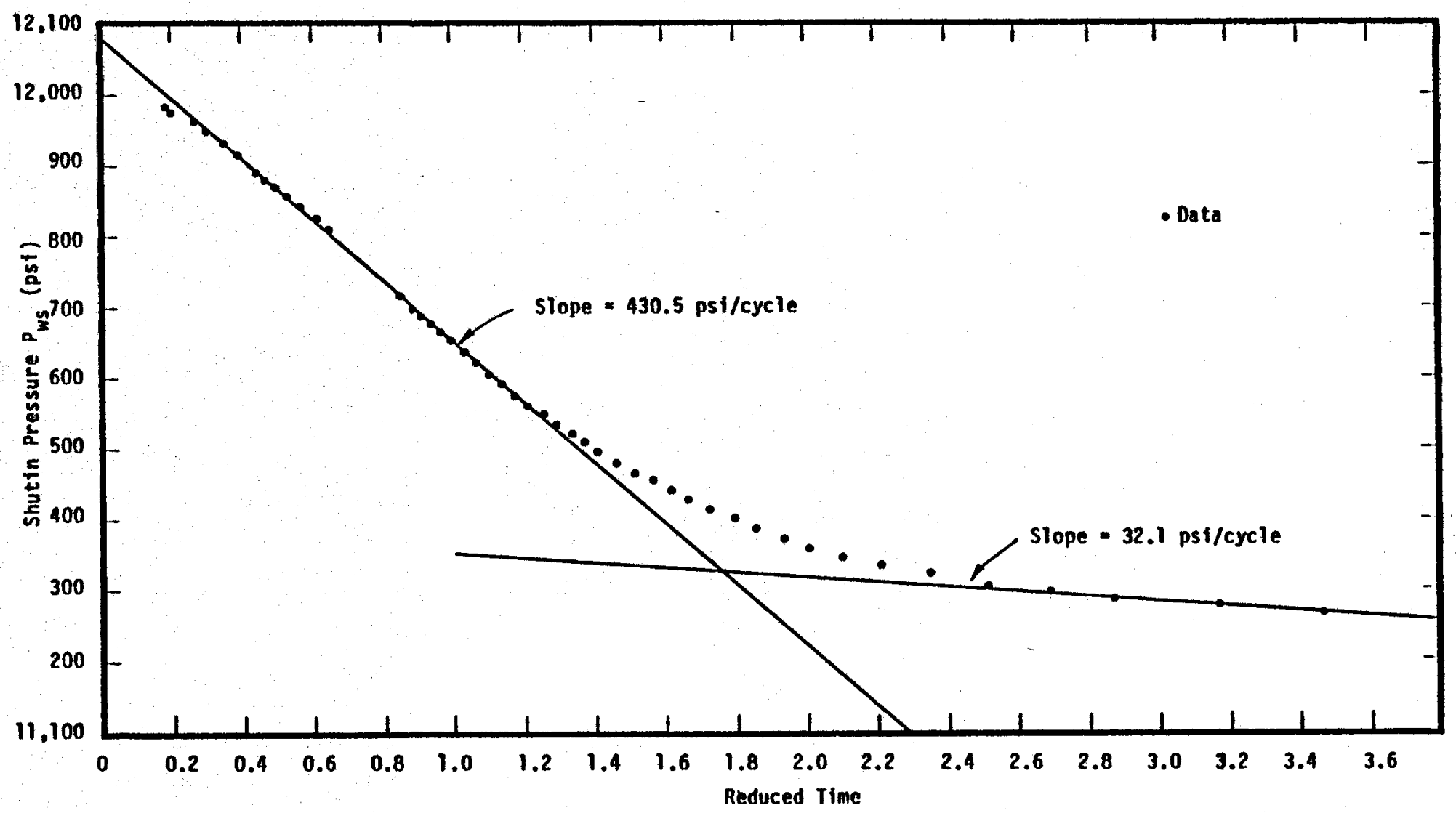

Figure 1. Buildup Data for MG-T/DOE Amoco Fee No. 1 Well (Initial Flow Test). 


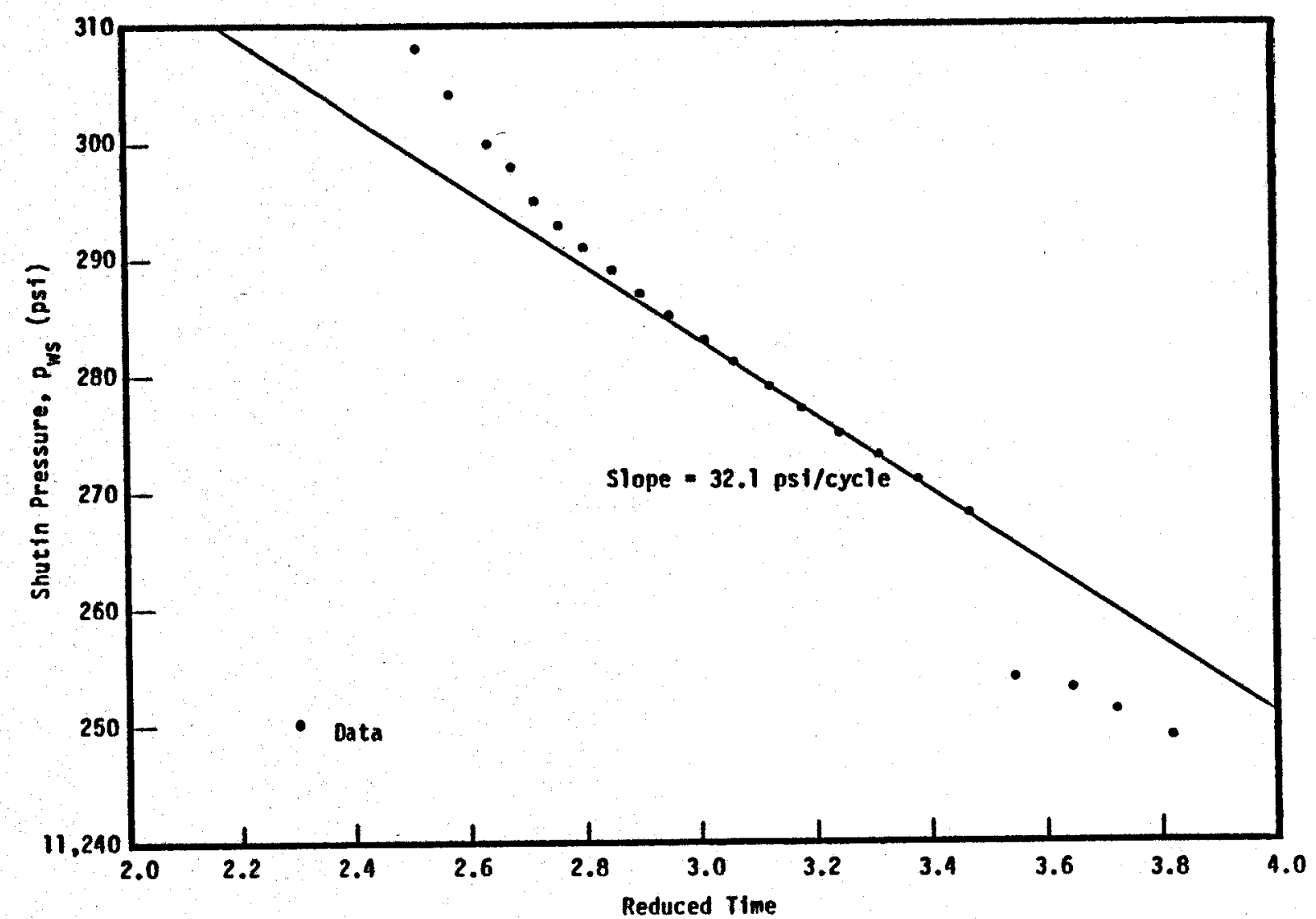

Figure 2. Early-Time Buildup Data for MG-T/DOE Amoco Fee No. 1 Well (Initial Flow Test). 


$$
\begin{aligned}
& \frac{k h}{\mu}=\frac{162.6 q_{N} B}{m}=\frac{162.6 \times 2610 \times 1.041}{32.1}=13,760 \frac{\mathrm{md} \mathrm{ft}}{c p} \\
& k=\frac{13760 \times \mu}{h}=\frac{13760 \times 0.296}{27}=150.9 \mathrm{md}
\end{aligned}
$$

With $p_{1 ~ h r}=11,310 \mathrm{psi}$ and $p_{w f}=11,141 \mathrm{psi}$, we obtain for skin factor $s$ :

$$
S=1.151\left[\frac{P_{1 h r}-P_{w f}}{m}-\log \frac{k}{\emptyset \mu C_{T} r_{W}^{2}}+3.23\right]=-1.54
$$

The pressure bulldup data start deviating from the first straight line segment at approximately $\Delta t=0.15$ hours. The radius investigated by the buildup test at this point in time is approximately given by (see Earlougher [1977]):

$$
r_{\text {inv }}=\left(\frac{0.00105 \mathrm{k} \Delta t}{{ }_{\mu} C_{T}}\right)^{1 / 2}=\left(\frac{0.00105 \times 150.9 \times 0.15}{0.22 \times 0.296 \times 6.5 \times 10^{-6}}\right)^{1 / 2}=240 \mathrm{ft}
$$

This implies that the permeability obtained from the first straight line segment applies within a circular region centered at the well of radius ( $r$ trans' approximately equal to $240 \mathrm{ft}$. In the following, we will present an alternative procedure for estimating $r_{\text {trans }}$.

The second straight line segment has a slope of 430.5 psi/cycle. This yields for "far-field" permeability:

$$
\begin{aligned}
\frac{k h}{\mu} & =\frac{162.6 \times 1.041 \times 2610}{430.5}=1026 \frac{\mathrm{md}-\mathrm{ft}}{\mathrm{cp}} \\
k & =\frac{1026 \times 0.296}{27}=11.25 \mathrm{md}
\end{aligned}
$$

We will now assert that the effect of the high permeability zone near the wellbore can be represented by an equivalent skin $\mathrm{s}_{\mathrm{eq}}$. 
With $p_{1 h r}=11,153 \mathrm{psi}$ (extrapolated from the second straight line segment) and $p_{w f}=11,141 \mathrm{ps}$, we obtain for $s_{\mathrm{eq}}$ :

$$
\begin{aligned}
s_{e q} & =1.151\left[\frac{11,153-11,141}{430.5}\right. \\
& \left.-\log \frac{11.25}{0.22 \times 0.296 \times 6.5 \times 10^{-6}(5.5 / 24)^{2}}+3.23\right]=-6.27
\end{aligned}
$$

The equivalent skin factor is related to "near wellbore" permeability $k_{1}$, "far-field" permeability $k_{2}$, transition radius $r_{\text {trans }}$ and wellibore radius $r_{w}$ as follows:

$$
\frac{k_{2}}{k_{1}}=\frac{s_{\mathrm{eq}}}{\ln \left(\frac{r_{\text {trans }}}{r_{w}}\right)}+1
$$

With $k_{1}=150.9 \mathrm{md}, k_{2}=11.25 \mathrm{md}, s_{\text {eq }}=-6.27$ and $r_{w}=$ $(5.5 / 24 \mathrm{ft})$, we obtain for $r_{\text {trans }}$ :

$$
r_{\text {trans }}=\exp \left[\frac{s_{e q}}{\left(k_{2} / k_{1}-1\right)}+\ln r_{w}\right]=200 \mathrm{ft} \text {. }
$$

The above value for $r_{\text {trans }}(200 \mathrm{ft})$ is of the same order as that calculated on the basis of the observed pressure deviations from the first straight line segment.

The principal results of the preceding analysis can be surmarized as follows:

(1) The near wellbore permeability is about $150 \mathrm{md}$, and applies within a radius of approximately $200 \mathrm{ft}$ from the wellbore. The far-field permeability (radius > 200 $\mathrm{ft}$ ) is, however, only about $11 \mathrm{md}$. 
(ii) The well is slightly stimulated (skin factor $s=$ - 1.54). The negative skin factor may represent the presence of a very high permeability zone in the immediate vicinity of the wellbore.

(iii) No reservoir boundaries can be inferred from the initial test. 


\section{HISTORY - MATCH CALCULATIONS}

In this section, we will employ the formation properties derived from the buildup data (Section II) in the reservoir simulator MUSHRM to match the observed drawdown/buildup pressures and flow rates. For simulation purposes, the reservoir is regarded to be a right circular cylinder with height $h=27 \mathrm{ft}$ and radius $R=$ $3,000 \mathrm{ft}$. The radius $R$ is chosen sufficiently large that no signal reaches the outer boundary of the reservoir for the drawdown/buildup times of interest. [The radius investigated $r_{\text {inv }}$ during buildup is approximately given by:

$$
r_{i n v}=\left(\frac{0.00105 \mathrm{k} \Delta t}{\delta \mu C_{T}}\right)^{1 / 2}=\left(\frac{0.00105 \times 11.25 \times 184}{0.22 \times 0.296 \times 6.5 \times 10^{-6}}\right)^{1 / 2}
$$

$-2270 \mathrm{ft}$.

The reservoir is represented by a 50 zone $\left(\Delta r_{1}=\Delta r_{2}=\ldots=\right.$ $\Delta r_{10}=50 \mathrm{ft} ; \Delta r_{11}=\Delta r_{12}=\ldots=\Delta r_{40}=60 \mathrm{ft} ; \Delta r_{41}=$ $\Delta r_{42}=\ldots=\Delta r_{50}=70 \mathrm{ft}$ ) radial grid. The outer boundary is assumed to be impermeable and insulated; this boundary condition does not affect the result. The production well is located at the geometric center of the first grid block.

The reservoir rock is taken to be a sandstone with the following properties:

Rock
$\left.\mathrm{kg} / \mathrm{m}^{3}\right)$ grain density, or $=165.4 \mathrm{ibm} / \mathrm{ft}^{3} \quad l=2.65 \times 10^{3}$

Initial porosity, $\phi_{0}=0.22$

Rock grain specific heat, $C_{v r}=0.23 \mathrm{Btu} / 7 \mathrm{bm}^{\circ} \mathrm{F} \quad(=0.963$ $\mathrm{kJ} / \mathrm{kg}^{\circ} \mathrm{C}$ )

Initial permeability, $k_{0}=$ 
Uniaxial formation compressibility, $C_{m}=10^{-6} \mathrm{psi}-1$ $\left(\sim 0.145 \times 10^{-9} \mathrm{~Pa}^{-1}\right)$

Skin factor, $s=-1.54$

A drop in pore pressure causes a reduction in porosity 6 and the permeability $k$. The instantaneous porosity $\phi$ and permeability $k$ are given by the following relations:

$$
\begin{aligned}
& \frac{\partial \phi}{\partial t}=(1-\phi) c_{m} \partial p / \partial t \\
& k=k_{0}\left(\frac{\phi}{\phi_{0}}\right)^{3}\left(\frac{1-\phi_{0}}{1-\phi}\right)^{2}
\end{aligned}
$$

where

$$
\begin{aligned}
& p=\text { fluid pressure } \\
& t=\text { time }
\end{aligned}
$$

Al though in the present case no gas is expected to evolve out of solution, we give in Table 1 relative permeabilities for water/ gas to illustrate the effects of the presence of any free gas in the pores. These relative permeabilities are based on measurements reported by Roberts [1980] on several cores obtained from the Pleasant Bayou (Brazoria County, Texas) wells. Table 1 shows that the gas phase remains essentially imobile for $s_{g} \leq 0.235$ (= residual gas saturation), and the 1iquid-phase relative permeability decilines dramatically with small amounts of free gas in the pores. 
Table 1

RELATIVE PERMEABILITIES

$\begin{array}{lll}\text { Free Gas Saturation }\left(\mathrm{S}_{\mathrm{g}}\right) & \begin{array}{c}\text { Liquid Relative } \\ \text { Permeability }\left(\mathrm{k}_{\mathrm{rw}}\right)\end{array} & \begin{array}{c}\text { Gas Relative } \\ \text { Permeability }\left(\mathrm{k}_{\mathrm{rg}}\right)\end{array} \\ & 1 & 0 \\ 0.005 & 0.71 & 10^{-4} \\ 0.1 & 0.49 & 2 \times 10^{-4} \\ 0.235 & 0.12 & 5 \times 10^{-4} \\ 1 & 0 & 1\end{array}$

The reservoir fluid is a partially methane saturated brine with dissolved solids by mass of $S=0.1487$. (This corresponds to a TDS of approximately $165,000 \mathrm{ppm}$ at the standard conditions. See Appendix for details.) The initial pore pressure, temperature and methane mass fraction at a depth of $15,400.5 \mathrm{ft}$ are $p=12,082 \mathrm{psi}$ $(=833.02$ bars $), T=299^{\circ} \mathrm{F} \quad\left(=148.33^{\circ} \mathrm{C}\right)$, and $C=0.0016 \quad(=14.7$ $\mathrm{SCF} / \mathrm{STB}$ ). The reservoir is produced by a single 5.5 in well; the production history imposed in the simulation is given in Table A-2 of the Appendix. In the following, all pressures are referred to the $15,337 \mathrm{ft}$ datum; the initial pressure at this datum is 12,053 psil $=831.03$ bars $)$.

Figure 3 compares the calculated bottom-hole pressures with observed drawdown pressures. The agreement between the calculated and observed pressures, with the exception of the very early and very late drawdown times, is rather poor. This disagreement between the calculated and the measured drawdown pressures is really not surprising in view of the uncertainties in the flow rate data.

The observed and calculated buildup pressures are compared in Figure 4. In general, there is good agreement between the measured and simulated buildup pressures. The latter observation together 


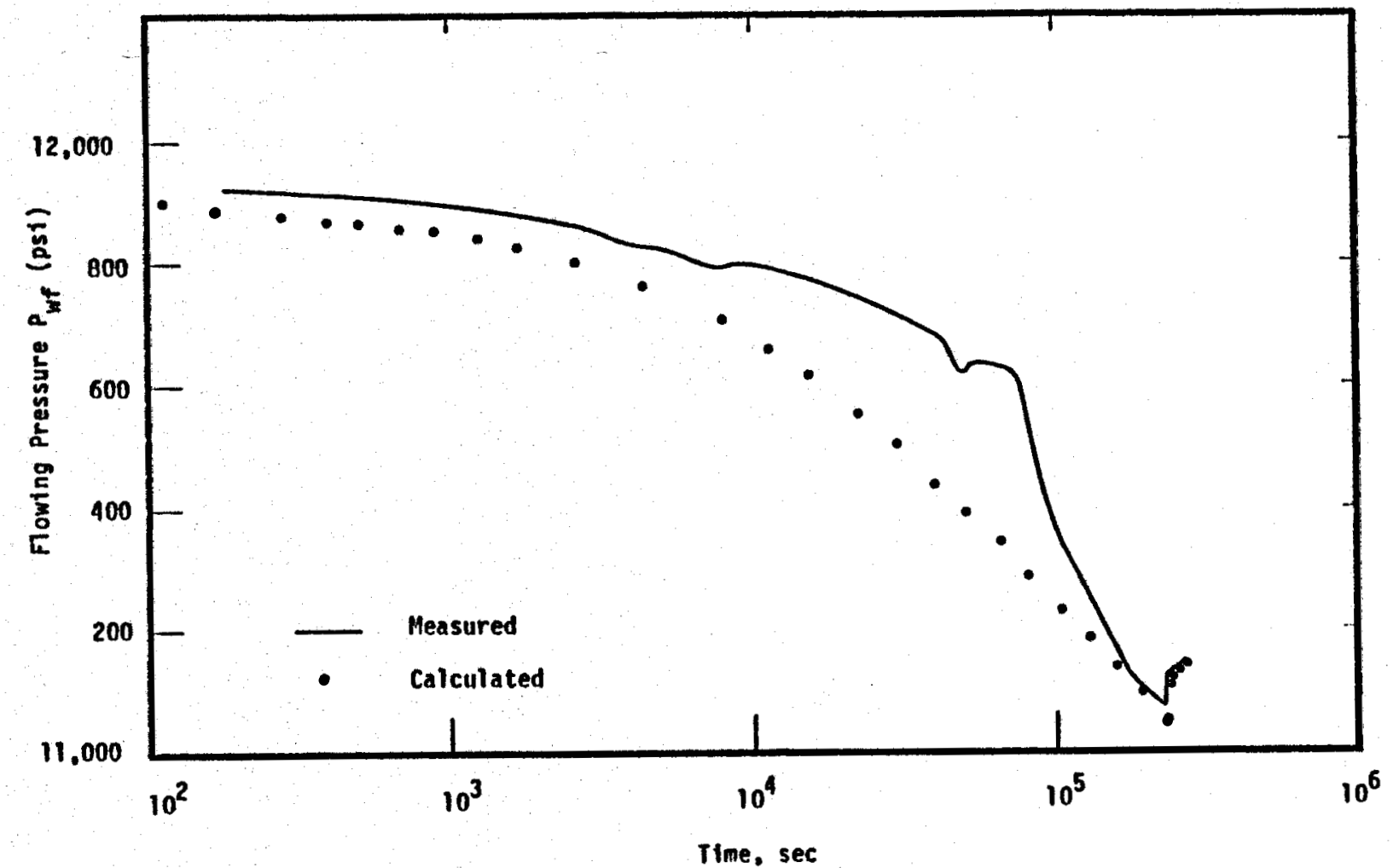

Figure 3. Comparison of Calculated Flowing Pressures with Measured Flowing Pressures for Initial Flow Test of MG-T/DOE Amoco Fee No. 1 Well. Abcissa Denotes Time from the Start of the Flow Test. 


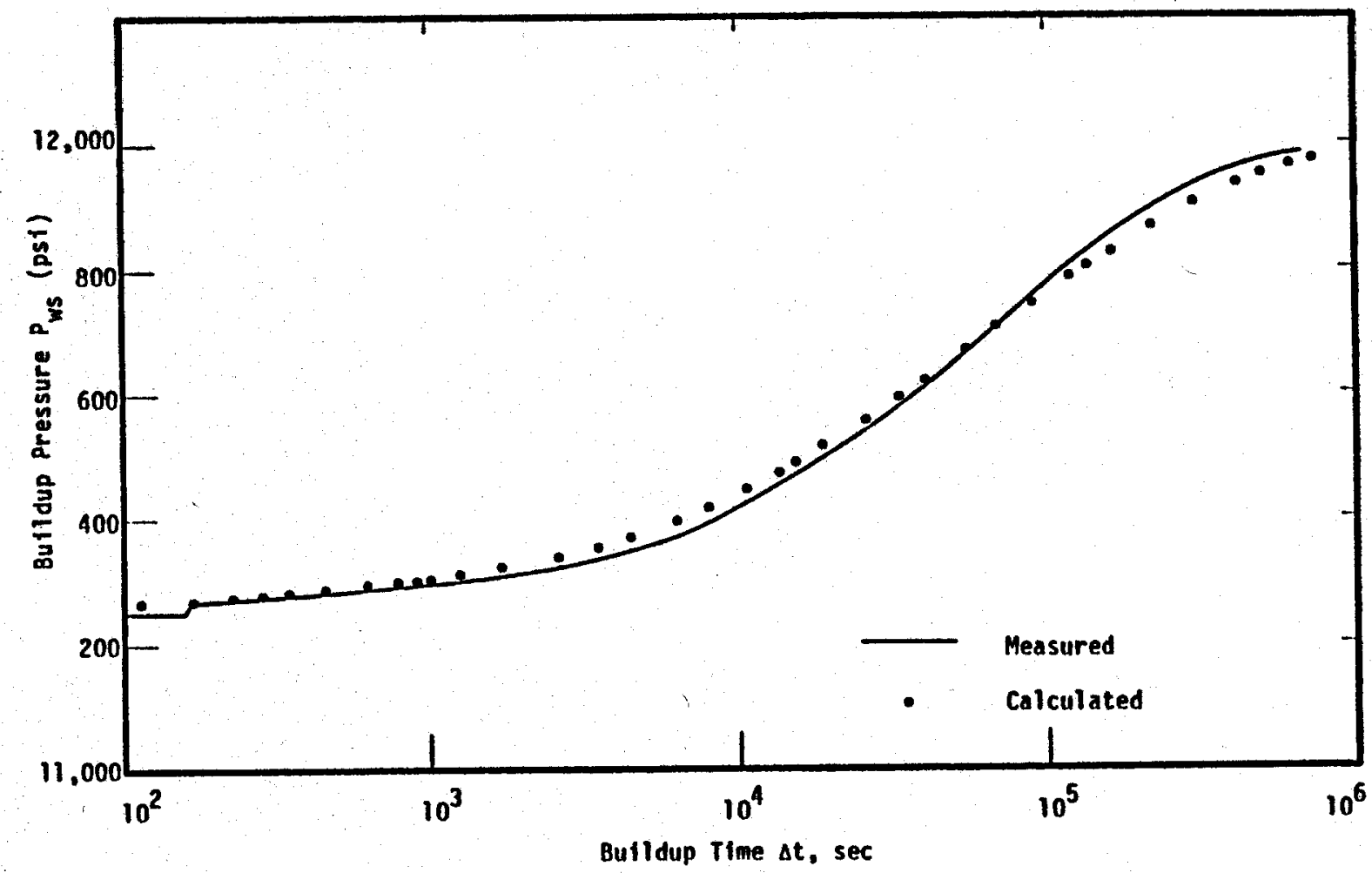

Figure 4. Comparison of Calculated Buildup Pressures with Measured Buildup Pressures for Initial Flow Test of MG-T/DOE Amoco Fee No. 1 Well. Abcissa Denotes Time from the Start of Shutin. 
with the good agreement between the calculated and measured pressure data at late drawdown times supports our view that the flow rate data are suspect.

The total calculated brine and methane production during the Initial flow test are $1.805 \times 10^{6} \mathrm{~kg}(=10,239$ STB $)$ and $2.893 \times$ $10^{3} \mathrm{~kg}\left(=1.504 \times 10^{5} \mathrm{SCF}\right)$ respectively. The calculated brine production is identical with the estimated actual production. The calculated methane content of the produced brine is approximately 14.7 SCF/STB ( $:$ assumed methane content of the reservoir fiuids). 


\section{CONCLUDING REMARKS}

Analysis of bulldup data from the Initial flow test indicates that the MG-T/DOE AMOCO Fee No. 1 Well penetrates a zone of relatively high permeability $(-150 \mathrm{md})$; this high permeability zone, however, extends to a radius of only about $200 \mathrm{ft}$ from the wellbore. The far-field permeability (i.e., for $r>200 \mathrm{ft}$ ) appears to be rather low $(\sim 11 \mathrm{md})$. No reservoir boundaries can be identified from the Phase I - Initial Flow Test; furthermore, the methane content of the reservoir fluid is somewhat uncertain $(9-15$ SCF/STB). The reservoir simulator MUSHRM together with the formation parameters inferred from the bulldup data were employed to history match the observed drawdown/butldup pressure and flow data. The calculated bulldup pressures closely agree with the measured values; the rather poor agreement between the measured and calculated drawdown pressures is ascribed to the uncertainties in the flow rate data. Recently, Phase II testing of the subject well has been completed; the data from this test phase should be helpful in identifying atleast some of the reservoir boundaries, and further refining the estimates for formation parameters. 


\section{REFERENCES}

DURRETT, L. R. and C. 0. Durham, Jr, "Geopressured - Geothermal Test Plan: MG-T/DOE AMOCO Fee No. 1. Wel1, Sweet Lake Prospect, Cameron Parish, Louisiana," Magma-Gulf Technadril, Houston, Texas, Report, 1981.

EARLOUGHER, R. C., Jr., Advances in Well Test Analysis, Monograph No. 5, Society of Petroleum Engineers of AIME, Dallas, Texas, 1977.

PRITCHETT, J. W., S. K. Garg, M. H. Rice and T. D. Riney, "Geopressured Reservoir Simulation," Systems, Science and Software, La Jolla, California, Report SSS-R-79-4022, 1979.

ROBERTS, B. W., "Relative Permeability Measurements of Texas Gulf Coast Sandstones at Low Free Gas Saturations," Center for Earth Sciences and Engineering - Division for Rock Mechanics, The University of Texas at Austin, Report No. UT 80-2, 1980. 
APPENDIX

INITIAL FLOW TEST DATA NOTES

I. Completed Interval: $15,387-15,414 \mathrm{ft}$

Net Sand Thickness: $27 \mathrm{ft}$

Mean Reservoir Depth: $15,400.5 \mathrm{ft}$

Rock Porosity 0 : 0.22

Well Radius $r_{W}=2.75$ in $(0.06985 \mathrm{~m})$

11. Since all pressures are measured at 15,337 ft datum, this datum is employed in most of the calculations in this report. Pressures at a datum other than 15,337 ft are calculated by using a correction factor of $0.46 \mathrm{psi} / \mathrm{ft}$.

III. Initial Pressure Data:

$p_{i}(15,387 \mathrm{ft}$, measured $)=12,053$ psi $(=831.03$ bars $)$

$p_{1}(15,400.5 \mathrm{ft}$, calculated $)=12,082$ psi $(=833.02$ bars $)$

IV. Initial Reservoir Conditions $(15,400.5 \mathrm{ft}$, datum):

$p_{f}=12,082$ psi ( $(=833.02$ bars $)$

$T_{i}$ (measured) $=299^{\circ} \mathrm{F}\left(=148.33^{\circ} \mathrm{C}\right)$

$S$ (salinity by mass) $=0.1487$

$C$ (methane content): see below.

v. At standard conditions ( $p=14.7 \mathrm{psi}, T=60^{\circ} \mathrm{F}$ ) with $\mathrm{S}=$ 0.1487 , the $s^{3}$ equation-of-state gives

$$
\begin{aligned}
& P_{\text {Brine }}=1.1088 \mathrm{gm} / \mathrm{cm}^{3}(=176.287 \mathrm{~kg} / \mathrm{STB}) \\
& \text { Total Dissolved Solids }=S \rho_{B \text { rine }}=165,000 \mathrm{ppm} \\
& \text { Specific Volume of Methane }=52.0 \mathrm{SCF} / \mathrm{kg}
\end{aligned}
$$


VI. Methane Content of Resevoir Fluids

Given $P_{j}, T_{i}$ and $S$ (see IV above), the methane mass fraction at saturation a sat may be calculated by using the $s^{3}$ equation-of-state data. This yields:

$a_{\text {sat }}=0.257465 \times 10^{-2}$

Thus, at saturation we have:

$\frac{\text { SCF of Methane }}{\text { STB }}=\frac{52.00 \times 0.257465 \times 10^{-2}}{5.6726 \times 10^{-3}\left(1 .-0.257465 \times 10^{-2}\right)}=23.7$

The brine produced during the initial flow test was substantially less than saturated with respect to methane (i.e., 9-15 SCF/STB rather than 23.7 SCF/STB at saturation under initial reservoir conditions). In view of this, we will assume that the methane mass fraction of reservoir fluids $C$ is approximately equal to $0.16 \times 10^{-2}$ (1.e., -14.7 SCF/STB).

VII. Reservoir Fluid Density, Pressure Gradient and Formation Volume Factor

With $p_{i}=12,082 \mathrm{psi}, T_{i}=299^{\circ} \mathrm{F}, S=0.1487$ and $C=0.16$ $\times 10^{-2}, s^{3}$ equation-of-state data yields:

Initial Fluid Density, $\rho_{j}=1.0656 \mathrm{gm} / \mathrm{cm}^{3}(\approx 169.421$ $\mathrm{kg} / \mathrm{bbl})$

Pressure Gradient $=0.462 \mathrm{pst} / \mathrm{ft}$

Formation Volume Factor $B=176.287 / 169.421=1.041$ 
VIII. At reservoir conditions, the $s^{3}$ equation-of-state gives the following value for fluid viscosity: $\mu=0.296 \mathrm{cp}$

\section{Reduction of Flow Data to Standard Conditions}

During the initial flow test, brine flow was recorded by a Halliburton turbine flow meter; the total brine production during the three-day test was 11,324 barrels. However, it should be noted that the flow meter was approximately $250 \mathrm{~B} / \mathrm{D}$ off zero, and could not be zeroed; the actual brine production is estimated to be 10,573 barrels rather than 11,324 barrels. In the following, the indicated flow rates were accordingly adjusted to give a total brine production of 10,573 barrels. In order to convert the measured barrels $Q_{\text {meas }}$ (actually the adjusted brine production) to stocktank barrels, the following procedure was employed:

1. For a given time interval, select the average pressure $P$ (Psi) and temperature $T\left({ }^{\circ} \mathrm{F}\right)$ at which the flow data was recorded. (According to information supplied to us, pressure $P$ and temperature $T$ averaged around 4000 psi and $214^{\circ} \mathrm{F}$ respectively during the initial flow test.)

2. Given $P$ and $T$, use the $S^{3}$ equation-of-state to calculate the liquid density $\rho(\mathrm{kg} / \mathrm{bbl})$, and the mass fraction of the methane $\left(a_{s}\right)$ dissolved in the brine.

3. The mass of the brine $M_{B}$ (less dissolved methane) is given by $Q_{\text {meas }}\left(1-a_{s}\right)_{D}$. Given $M_{B}$, the brine volume at standard conditions is calculated by dividing $M_{B}$ by the brine density at standard conditions ( - 176.287 $\mathrm{kg} / \mathrm{STB}$ ). 
Table A-1 gives the reduced flow data for the initial flow test.

The pressure drawdown and production rate data are plotted in Figure A-1. It is obvious from Figure A-1 that something is wrong; the Indicated changes in flow rate (with the exception of the last change on 6/22/1981 at about 12:00 hours) are not reflected in the pressure response. It, therefore, appears that the flow rate data are of doubtful validity. Accordingly, we will average the flow data of Table A-1 over two time intervals (1.e., 1. From the start of flow test to 12:00 hours on 6/22 and 2. From 12:00 hours on 6/22 to the end of the flow test). A1so, we require mass withdrawal rate from the reservoir. Given $Q_{c}$ (STB) from Table A-1, mass withdrawal rate can be computed as follows:

1. Calculate brine flow rate $q_{c}$ at standard conditions by dividing $Q_{c}$ by the time interval (days).

2. Given $q_{C}(S T B / D)$, calculate brine mass flow rate $\dot{M}_{B}$ by $\dot{M}_{B}=q_{C} \times 176.287 /(24 \times 3600) \mathrm{kg} / \mathrm{sec}$

3. To obtain the total flow rate $\dot{M}_{T}(\mathrm{~kg} / \mathrm{sec})$ divide $\dot{M}_{B}$ by $(1-C)$, where $C(=0.0016)$ denotes the mass fraction of methane at reservoir conditions.

Table A-2 gives the averaged mass flow data. 


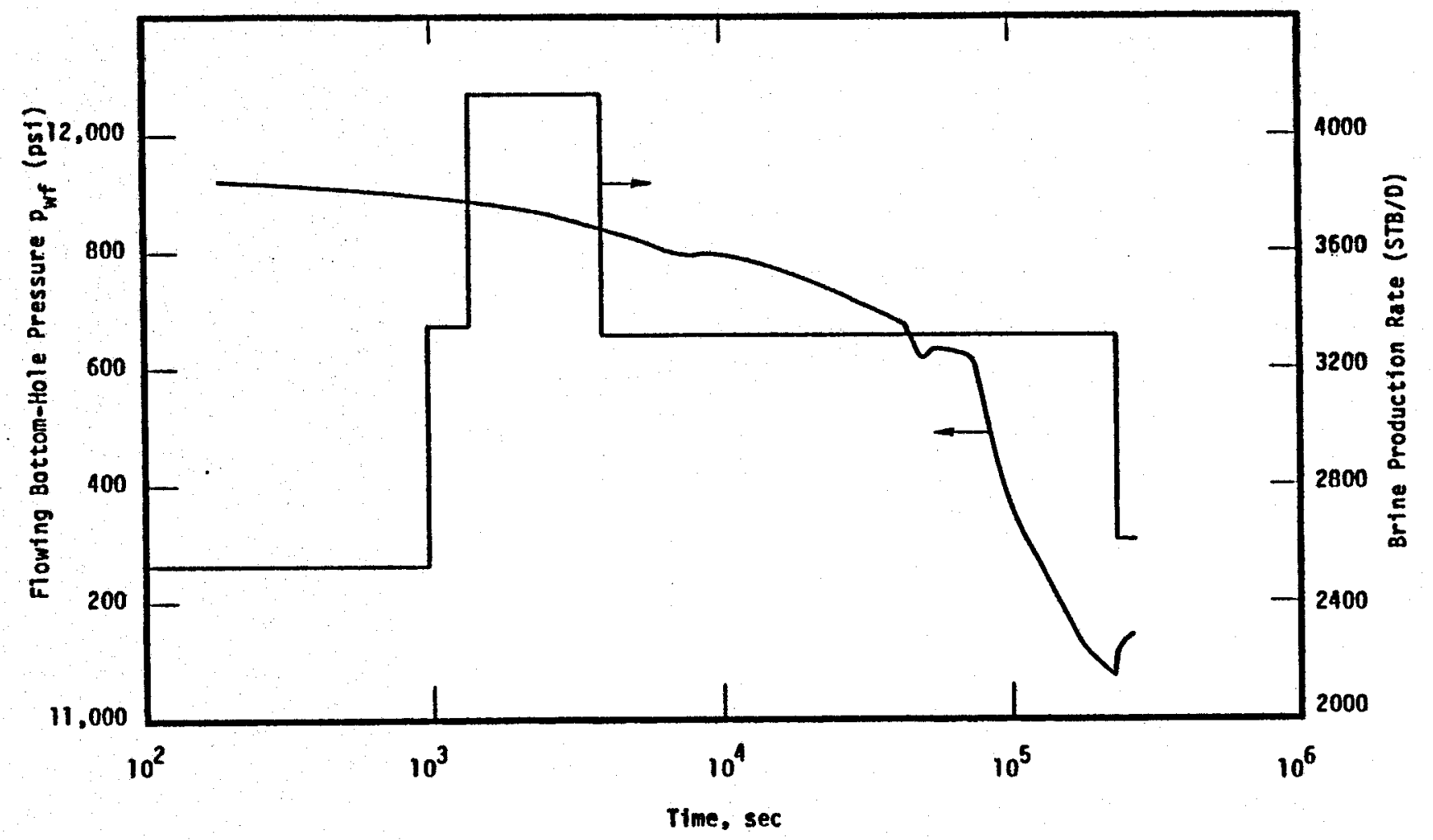

Figure A-1. Pressure Drawdown and Brine Production Rate Data for Initfal Flow Test of MG-T/DOE Amoco Fee No. 1 Well. Abcissa Denotes Time from the Start of Flow Test at 18:18 Hours on $6 / 19 / 1981$. 
Table A-1

FLOW DATA FOR INITIAL FLOW TEST

$$
\text { t, } Q_{\text {meas }} P(p s i)\left(1-a_{s}\right)_{p} \quad \dot{M}_{B} \quad Q_{C} \quad q_{C} \quad \sum Q_{C}
$$

Date/Hours Minutes $\underline{b b l} \underline{T\left({ }^{\circ} \mathrm{F}\right)} \mathrm{kg} / \mathrm{Bbl} \quad \underline{\mathrm{kg}} \underline{\text { STB }} \underline{\text { STB/D }}$

$\begin{array}{llllllllll}6 / 19 & 18: 18 & 0 & 293 & 4000 & 170.717 & 50,020 & 284 & 2522 & 284\end{array}$

$6 / 19 \quad 21: 00 \quad 162 \quad 214$

$\begin{array}{llllllllll}6 / 19 & 21: 00 & 162 & 144 & 4000 & 170.717 & 24,583 & 139 & 3347 & 423\end{array}$

$6 / 19 \quad 22: 00 \quad 222 \quad 214$

$\begin{array}{llllllllll}6 / 19 & 22: 00 & 222 & 1250 & 4000 & 170.717 & 213,396 & 1211 & 4150 & 1634\end{array}$

$6 / 20 \quad 05: 00 \quad 642 \quad 214$

$\begin{array}{llllllllll}6 / 20 & 05: 00 & 642 & 1835 & 4000 & 170.717 & 313,266 & 1777 & 3554 & 3411\end{array}$

$6 / 20 \quad 17: 00 \quad 1362 \quad 214$

$\begin{array}{llllllllll}6 / 20 & 17: 00 & 1362 & 6147 & 4000 & 170.717 & 1,049,397 & 5953 & 3322 & 9364\end{array}$

$6 / 22 \quad 12: 00 \quad 3942 \quad 214$

$\begin{array}{llllllllll}6 / 22 & 12: 00 & 3942 & 904 & 4000 & 170.717 & 154,328 & 875 & 2610 & 10,239\end{array}$

$\begin{array}{llll}6 / 22 & 20: 03 & 4425 & 214\end{array}$

Totals

$$
73.75 \quad 10573
$$

$1,804,990 \quad 10239$

10,239

hours 
Table A-2

AVERAGED FLOW DATA FOR INITIAL FLOW TEST

\begin{tabular}{|c|c|c|c|c|c|c|}
\hline Date/Hours & $t, \min$ & $Q_{c}$, STB & $q_{c}, S T B / D$ & $\dot{M}_{B, \mathrm{~kg} / \mathrm{s}}$ & $\dot{\mathrm{M}}_{\mathrm{T}, \mathrm{kg}}$ & $\sum Q_{c}$ \\
\hline $6 / 19 \quad 18: 18$ & 0 & 9364 & 3420 & 6.979 & 6.990 & 9364 \\
\hline $6 / 22 \quad 12: 00$ & 3942 & & & & & \\
\hline $6 / 22 \quad 12: 00$ & 3942 & 875 & 2610 & 5.325 & 5.334 & 10,239 \\
\hline $6 / 22 \quad 20: 03$ & 4425 & & & & & \\
\hline Totals & $\begin{array}{l}73.75 \\
\text { hours }\end{array}$ & 10239 & & & & 10,239 \\
\hline
\end{tabular}

